\title{
Lesões gástricas em suínos: Ocorrência e relação com o gênero, peso ao abate e presença de helicobacter spp. ${ }^{1}$
}

\author{
Gastric lesions in swine: occurrence and correlation with sex, weight \\ and Helicobacter spp infection.
}

\author{
Letícia Yamasaki²; Felipe Malavolta de Souza Assis³, Victor José Vieira Rosseto³; \\ Ana Paula F.R.L. Bracarense ${ }^{4 *}$
}

\section{Resumo}

O objetivo deste estudo foi determinar a ocorrência de lesões gástricas em suínos de abate e verificar a relação das lesões com o gênero, o peso da carcaça e a presença de Helicobacter spp na mucosa gástrica. Foram colhidos e examinados 236 estômagos de suínos. As lesões da pars esophagea e região glandular foram classificadas conforme a severidade em graus $0,1,2$ e 3 . Fragmentos das regiões aglandular e glandular foram processados para exame histológico e para pesquisa de Helicobacter spp. A análise macroscópica revelou que 203 (86.1\%) estômagos apresentavam algum tipo de lesão. A ocorrência de erosões e úlceras na região aglandular foi observada em 104 (44.1\%) animais e na região glandular em 22 (9.3\%). A ulceração na região gastroesofágica estava presente em 45 animais (19.1\%), dos quais 25 (21.1\%) eram machos e 20 (16.5\%) fêmeas. O peso médio da carcaça foi de $82.7 \mathrm{Kg}$ nos animais sem lesões e com paraqueratose na pars esophagea e de $79.5 \mathrm{Kg}$ nos animais com erosões e ulcerações. Utilizando a coloração de Warthin-Starry, observamos Helicobacter spp na mucosa gástrica de $112(47.5 \%)$ amostras. Destas, 54 (48.2\%) foram classificadas como grau 2 ou 3 (pars esophagea) e 58 $(51.8 \%)$ como grau 0 e 1 . Dos animais positivos para o Helicobacter spp, $26(23.2 \%)$ apresentavam úlceras na pars esophagea e 24 (21.4\%) apresentavam a mucosa sem alterações. Dos 124 (52.5\%) animais negativos, 50 (40.3\%) foram classificados como grau 2 ou 3 e $74(59.7 \%)$ como grau 0 ou 1 . A análise estatística revelou que não há diferença significativa entre suínos com ou sem lesões gástricas em relação à presença de Helicobacter spp, gênero e peso da carcaça.

Palavras-chave: Suínos, Helicobacter spp., lesões gástricas.

Apoio financeiro: CNPq, CAPES e PROPPG/UEL.

Aluna do programa de Pós-graduação em Ciência Animal (área de concentração: Sanidade Animal; nível mestrado), UEL..

3 Bolsista iniciação científica CNPq, aluno do curso de Medicina Veterinária da Universidade Estadual de Londrina - UEL.

${ }^{4}$ Laboratório de Anatomia Patológica, DMVP, CCA, UEL. Londrina, Paraná, Brasil. Caixa-postal: 6001. Tel: + 43 3371-4062. Email: anapaula@uel.br.

* autor para correspondência 


\begin{abstract}
The aim of this study was to investigate the association between the lesions of the gastric mucosa in slaughter pigs and sex, carcass weight and presence of Helicobacter spp. Stomachs from 236 swine were examined. Gastroesophageal lesions were classified in agreement severity in grade 0,1,2 and 3 . Fragments from the aglandular and glandular area were processed for histology and for identification of Helicobacter spp in tissue sections. Macroscopic analysis revealed 203 (86.1\%) stomachs with some degree of lesion. Grade 2 and 3 lesions were observed in 104 (44.1\%) animals. Grade 3 lesions were observed in $25(21.1 \%)$ castrated males and $20(16.5 \%)$ females. The average carcass weight of animals with grade 0 and 1 lesions and grade 2 and 3 was $82,5 \mathrm{Kg}$ and 79,5 $\mathrm{Kg}$, respectively. One hundred and twelve $(47.5 \%)$ pigs were positive for Helicobacter spp. by Warthin-Starry stain method ; among them, $54(48.2 \%)$ had grade 2 and 3 lesions; and $58(51.8 \%)$ had grade 0 and 1 lesions. One hundred and twentyfour (52.5\%) were negative for Helicobacter spp; among them 50 (40.3\%) had grade 2 and 3 lesions, and $74(59.7 \%)$ had grade 0 and 1 . There was no significant difference between pigs with and without gastric lesions in regard to the presence of Helicobacter spp, sex and weight.
\end{abstract}

Key words: Swine, Helicobacter spp., gastric lesions.

\section{Introdução}

Lesões envolvendo a pars esophagea de suínos foram descritas a partir da década de 50 em diversos países, sendo associadas à produção intensiva. $\mathrm{O}$ impacto econômico das doenças gástricas em suinocultura se dá pela taxa de mortalidade associada à forma hemorrágica aguda em matrizes (KOWALCZYK, 1969) e pelas perdas econômicas decorrentes de anemia crônica, anorexia e diminuição do ganho de peso (O'BRIEN, 1993). Entretanto, existem controvérsias, visto que Guise et al. (1997) e Friendship et al. (1999) não constataram relação entre ulceração gástrica e queda no desempenho.

Alterações como paraqueratose, erosões e ulcerações gástricas são encontradas em 43,7 a $77,4 \%$ da população suína do Brasil (CARVALHO et al., 1999). Dentre estas, as úlceras gástricas são reconhecidas como uma importante doença em suínos, com ocorrência variando de $13 \%$ a $22,9 \%$ (MUGGENBURG et al., 1964; ARGENZIO e EISEMANN, 1996; GUISE et al., 1997). No Brasil, a ocorrência dessa lesão específica varia de 5,5\% a 23,5\% (CIACCI et al., 1991; ROPPA et al., 1995; CARVALHO et al., 1999).

Desde os primeiros estudos sobre as doenças gástricas de suínos, observou-se que as lesões na pars esophagea eram mais freqüentes do que na região glandular (MUGGENBURG et al., 1964;
CARVALHO et al., 1999). A maior suscetibilidade desta região à injúria é atribuída à falta do muco protetor produzido pelo epitélio mucossecretor, presente na região glandular, e a incapacidade do epitélio estratificado produzir quantidade suficiente de bicarbonato para neutralizar o ácido gástrico (EMBAYE et al., 1990). O número de animais que apresentam ulcerações em ambas as regiões é pequeno, sugerindo que os dois processos devem ter etiologias distintas (CARVALHO et al., 1999).

No Brasil, estudos demonstram a influência do gênero na freqüência de úlceras gastresofágicas, sendo esta maior em machos castrados que em fêmeas ou machos inteiros (MONTICELLI et al., 1995; CARVALHO et al., 1999). Porém, em estudos no exterior, outros autores não observaram esta influência (GUISE et al., 1997; FRIENDSHIP et al., 1999).

A descoberta da associação entre a infecção pelo Helicobacter pylori no homem e a presença de gastrites, úlceras e neoplasias como adenocarcinoma e linfoma gástrico despertou um grande interesse a respeito da participação de bactérias no desenvolvimento de gastropatias (MARSHAL e WARREN, 1984; SIMPSON et al., 1999). Atualmente o Helicobacter pylori é reconhecido como a maior causa de doenças da mucosa gástrica (ERNST et al., 2006), sendo a infecção essencial 
para o desenvolvimento de câncer gástrico no homem (BRENNER et al., 2004). Em suínos, a etiologia e fisiopatologia das úlceras gástricas permanecem incertas. No passado as pesquisas enfocaram fatores dietéticos e relacionados ao stress (ARGENZIO e EISEMANN, 1996). Recentemente, a ocorrência de lesões gástricas foi associada à presença de Helicobacter spp. (QUEIROZ et al., 1996).

A associação entre Helicobacter spp e a ocorrência de úlceras gastroesofágicas em suínos tem sido controversa. Estudos afirmam que as bactérias do gênero Helicobacter predispõem o estabelecimento de úlceras (BARBOSA et al.,1995; PARK et al., 2004; MALL et al., 2004). Entretanto, outros autores relatam que esta associação é inconsistente (MELNICHOUK et al., 1999; KRAKOWKA et al., 2005; SZEREDI et al., 2005).

O objetivo deste estudo foi determinar a ocorrência lesões gástricas em suínos de abate e verificar a relação das lesões com o gênero, o peso da carcaça e a presença de Helicobacter spp na mucosa gástrica.

\section{Material e Métodos}

Foram utilizados 236 estômagos de suínos, colhidos por conveniência durante o abate, em um frigorífico com Serviço de Inspeção Federal, localizado na macroregião de Londrina. Os animais eram de diversas linhagens, com idade entre 140 e 150 dias. Por ocasião da colheita das amostras foram anotados o gênero e o peso da carcaça. Os animais provinham de 19 municípios que foram agrupados em mesoregiões.

Os estômagos foram examinados externamente e incisados ao longo da curvatura maior para exame interno. As alterações macroscópicas de pars esophagea encontradas foram anotadas e classificadas conforme sua localização, tipo e gravidade, seguindo o modelo de classificação modificado de MORÉS et al. (2000) (quadro 1).

Quadro 1 - Classificação das alterações macroscópicas de estômago suíno, modificado de MORÉS et al. (2000). Londrina, Paraná, 2006.

\begin{tabular}{|c|c|c|}
\hline Escore & Pars esophagea & Região glandular \\
\hline Grau 0 & $\begin{array}{l}\text { Ausência de alterações macroscópicas, epitélio de aspecto liso e } \\
\text { brilhante. }\end{array}$ & Ausência de alteração \\
\hline Grau 1 & Paraqueratose, epitélio proliferado, rugoso e sem brilho. & $\begin{array}{l}\text { Hiperemia, edema e/ou hemorragia } \\
\text { da mucosa. }\end{array}$ \\
\hline Grau 2 & $\begin{array}{l}\text { Erosões com comprometimento de menos de } 33 \% \text { da região } \\
\text { gastresofágica. }\end{array}$ & Presença de erosões \\
\hline Grau 3 & $\begin{array}{l}\text { Ulcerações ativas ou crônicas em mais de } 33 \% \text { da região } \\
\text { gastresofágica. }\end{array}$ & Presença de ulcerações \\
\hline
\end{tabular}

Fragmentos de regiões pré-estabelecidas da pars esophagea, corpo, fundo e piloro foram colhidos e fixados em solução tamponada de formalina a 10\%. Nas amostras classificadas com lesão grau 3, tanto em região glandular quanto pars esophagea, foram colhidos também fragmentos da lesão para análise histológica. Os fragmentos foram então submetidos ao processamento histológico de rotina. Os cortes de $4 \frac{1}{4} 4 \mathrm{~m}$ de espessura foram corados pelo método de Wharthin-Starry (WS) para pesquisa de bactérias de formato espiralado nos fragmentos de mucosa gástrica. Os cortes foram examinados com objetiva de 100x. A superfície mucosa, região de fóvea e lúmen glandular foram examinados em toda a sua extensão.

Os percentuais de ocorrência de bactérias nos grupos com e sem lesão gástrica foram comparados pelo teste do Qui-quadrado, ficando estabelecido 5\% como nível de significância. 


\section{Resultados}

Ao exame macroscópico verificou-se que 203 $(86,1 \%)$ estômagos apresentavam algum tipo de lesão. As lesões de grau 1 foram as mais freqüentes em ambas as regiões, com 33,5\% na região de pars esophagea e $41,5 \%$ na região glandular. A

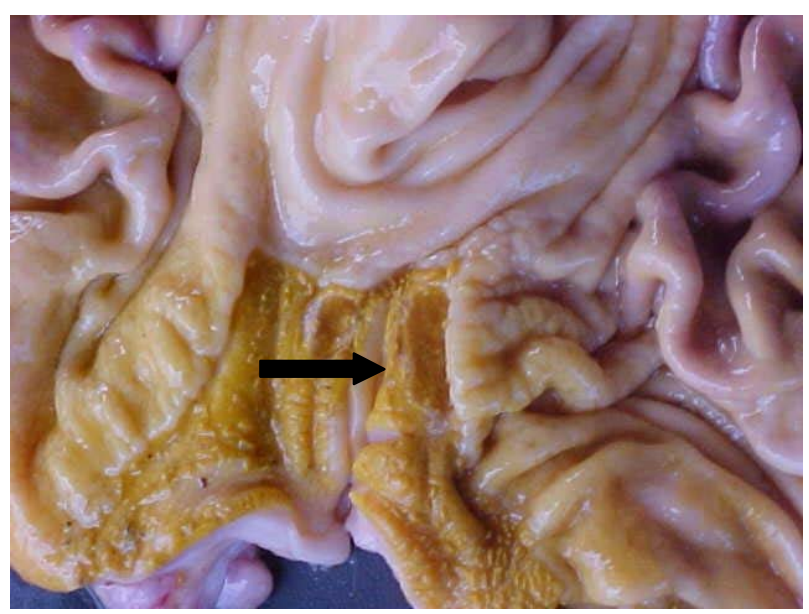

ocorrência de lesões de grau 2 e 3 na pars esophagea (Figura 1) foi observada em $104(44,1 \%)$ estômagos e na região glandular em 22 (9,3\%). As lesões de grau 3 na pars esophagea estavam presentes em 45 estômagos $(19,1 \%)$ e na região glandular em cinco $(2,2 \%)$ (Tabela 1$)$.

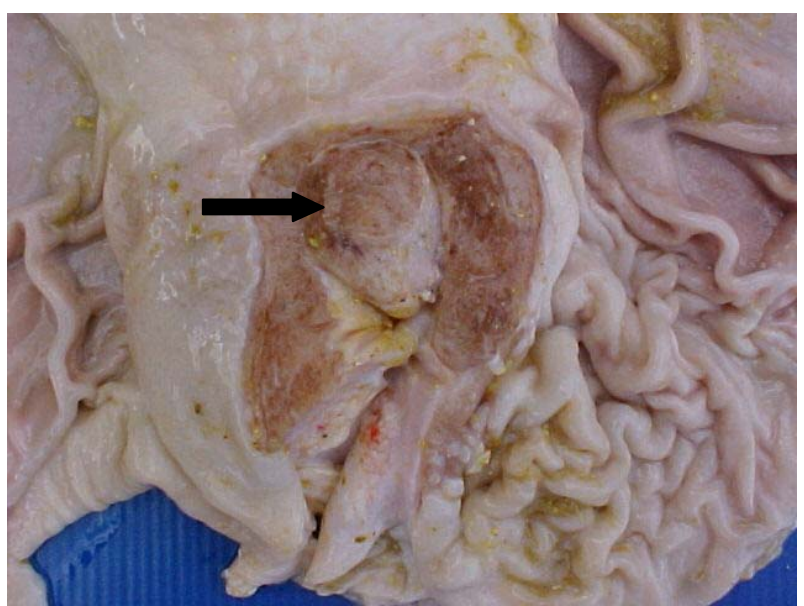

Figura 1 - Graus de lesão 2 e 3 (respectivamente) de estômago de suíno em idade de abate (setas); pars esophagea. Londrina, Paraná, 2006.

Quanto ao gênero, dos 236 animais avaliados, 115 eram machos e 121 fêmeas, sendo que 80\% dos machos e 75,2\% das fêmeas tinham algum grau de lesão macroscópica na pars esophagea. A ocorrência dos diferentes graus de lesão no estômago está descrita na tabela 1. À análise estatística não se evidenciou influência do gênero sobre a ocorrência de lesões gástricas.

Tabela 1 - Ocorrência de lesões de grau 1, 2 e 3 no estômago de suínos oriundos do Estado do Paraná, segundo o gênero. Londrina, Paraná, 2006.

\begin{tabular}{lccccc}
\hline & Gênero & Grau 1 (\%) & Grau 2 (\%) & Grau 3 (\%) & Total (\%) \\
\hline Aglandular* & Machos & $37(32,1)$ & $30(26)$ & $25(21,7)$ & $92(80)$ \\
& Fêmeas & $42(34,7)$ & $29(23,9)$ & $20(16,5)$ & $91(75,2)$ \\
\cline { 2 - 6 } & total & 79 & 59 & 45 & 183 \\
\hline Glandular** & Machos & $44(38,2)$ & $10(8,7)$ & $2(1,7)$ & $56(48,7)$ \\
& Fêmeas & $54(44,6)$ & $7(5,8)$ & $3(2,5)$ & $64(52,9)$ \\
\cline { 2 - 6 } & total & 98 & 17 & 5 & 120
\end{tabular}

*Qui-quadrado $=0,88 ; \mathrm{p}=0.6429$

$* *$ Qui-quadrado $=1.22 ; \mathrm{p}=0,5428$ 
Em relação ao peso médio da carcaça, verificouse que os animais com lesões na pars esophagea de grau 0 e 1 apresentaram peso médio de $82,7 \mathrm{~kg}$ e os com lesões de grau 2 e 3, 79,5 kg. A média de peso dos animais infectados por bactérias espiraladas foi de 78,9 $\mathrm{kg}$ e a dos não infectados $77 \mathrm{~kg}$. À análise estatística não se evidenciou influência da presença de lesões gástricas ou de Helicobacter spp sobre o peso médio da carcaça.

Utilizando a coloração de Warthin-Starry, constatou-se a presença de Helicobacter spp (Figura 2) colonizando a mucosa gástrica em 47,5\% (112/ 236) dos animais analisados. Os microrganismos foram observados principalmente na superfície mucosa e na região da fóvea do estômago glandular. A presença de Helicobacter spp foi verificada principalmente nas regiões de piloro, corpo e fundo, sendo que raramente foram observadas na região de pars esophagea.O número de amostras positivas para a presença de Helicobacter spp nos diferentes graus de lesão da região aglandular e glandular está descrito na tabela 2.

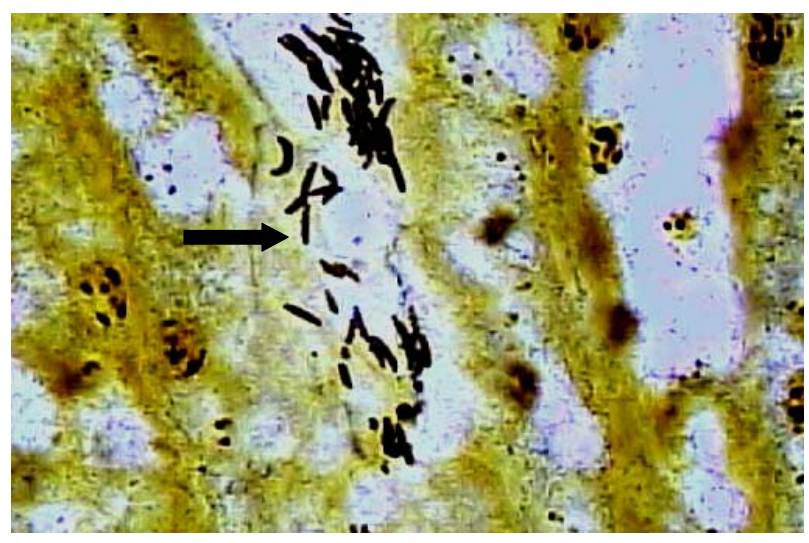

Figura 2 - Fotomicrografia de estômago de suíno corado pelo método de Warthin-Starry. Presença de bactérias de formato espiralado (seta) na glândula gástrica, objetiva 100X. Londrina, Paraná, 2006.

Dentre os 236 estômagos analisados, 45 (19,1\%) apresentavam ulcerações na região de pars esophagea, sendo que em 26 (57,7\%) verificamos a presença de Helicobacter spp. Na região glandular observamos lesões de grau 3 em cinco animais, sendo que em três observamos bactérias na mucosa gástrica. Quando analisamos as lesões de graus 0 e 1 de região glandular observamos que $100(46,7 \%)$ desses estômagos tinham Helicobacter spp. Já nos animais classificados como graus 0 e 1 de pars esophagea, constatamos a presença de Helicobacter spp em 58 $(43,9 \%)$ animais (Tabela 2).

Tabela 2 - Presença de Helicobacter spp na mucosa gástrica de suínos de abate com diferentes graus de lesão. Londrina, PR, 2006.

\begin{tabular}{lcccccc}
\hline & Presença de Helicobacter spp & Grau 0 & Grau 1 & Grau 2 & Grau 3 & Total \\
\hline Pars esophagea & Positivo & 24 & 34 & 28 & 26 & 112 \\
& Negativo & 29 & 45 & 31 & 19 & 124 \\
\cline { 2 - 6 } & Total & 53 & 79 & 59 & 45 & 236 \\
\hline Glandular** & Positivo & 49 & 51 & 9 & 3 & 112 \\
& Negativo & 67 & 47 & 8 & 2 & 124 \\
\cline { 2 - 7 } & Total & 116 & 98 & 17 & 5 & 236 \\
\hline
\end{tabular}

*Qui-quadrado $=2,64 ; \mathrm{p}=0,4502$

$* *$ Qui-quadrado $=2,61 ; \mathrm{p}=0,4554$

Dos 112 estômagos positivos para a presença da bactéria, $26(23,2 \%)$ apresentavam úlceras na pars esophagea e $24(21,4 \%)$ apresentavam a mucosa sem alterações. Constatamos úlceras de região glandular em três animais dos 112 em que se observou Helicobacter spp, e $49(43,7 \%)$ animais sem 
alteração macroscópica. A análise estatística não demonstrou influência da presença da bactéria sobre a ocorrência de lesões gástricas.

\section{Discussão}

A análise dos resultados revelou que $86,1 \%$ dos estômagos apresentavam algum grau de lesão, valor superior ao descrito por Carvalho et al. (1999), que relataram freqüência de $77,4 \%$. Em relação às lesões na pars esophagea, observamos que 44,1\% dos animais apresentavam lesões de grau 2 e 3 , sendo $19,1 \%$ de ulcerações. Estes resultados são semelhantes aos descritos em outros estudos (MUGGENBURG et al., 1964; ROPPA et al., 1995; CARVALHO et al., 1999). Poucas são as citações na literatura que se referem a alterações na região glandular. Entretanto, constatamos que 9,3\% dos animais apresentavam erosões e ulcerações de região glandular, ocorrência superior às relatadas anteriormente (MUGGENBURG et al., 1964; ROPPA et al., 1995; CARVALHO et al., 1999). A escassez de relatos caracterizando as lesões macroscópicas da região glandular pode ser um fator que influenciou nesta diferença de resultados.

Os percentuais de ocorrência de Helicobacter spp em suínos são bastante variáveis. A ocorrência da bactéria variou de 9,4 e 10,8\% segundo Queiroz et al. (1990) e Grasso et al. (1996). Cantet et al. (1999) observaram $80 \%$ de positividade para Helicobacter spp em um total de 60 amostras de estômagos suínos, utilizando a reação em cadeia pela polimerase (PCR). Young et al. (2001) encontraram resultado positivo em $63,8 \%$ das amostras, também utilizando PCR. A sensibilidade para o diagnóstico de Helicobacter spp varia de acordo com a metodologia utilizada. Segundo De Groote et al. (2000), a PCR é o método diagnóstico mais sensível e específico quando comparado a outros métodos utilizados para diagnóstico de infecção por Helicobacter spp. em animais. Neste trabalho, ao utilizarmos a impregnação argêntica como método diagnóstico, constatamos a presença de bactérias espiraladas na mucosa gástrica de 47,5\% dos animais avaliados. Resultado superior ao observado por Queiroz et al. (1990), que utilizaram metodologia diagnóstica semelhante e inferior ao relatado por Cantet et al. (1999) e Young et al. (2001), que utilizaram a PCR.

A associação entre Helicobacter spp e a ocorrência de úlceras gastroesofágicas em suínos tem sido controversa. Estudos afirmam que as bactérias do gênero Helicobacter predispõem o estabelecimento de úlceras (QUEIROZ et al., 1990; BARBOSA et al., 1995; PARK et al., 2004; MALL, et al., 2004). Entretanto, diversos autores afirmam que esta associação é inconsistente (MELNICHOUK et al., 1999; KRAKOWKA et al., 2005; SZEREDI et al., 2005). Os resultados encontrados sugerem que não há associação entre as lesões gástricas e o Helicobacter spp, pois o número de animais com lesões gástricas acompanhadas da presença do Helicobacter spp não foi significativamente diferente dos animais com lesões gástricas e sem a bactéria. A razão para esta diferença de resultados permanece incerta.

O mecanismo pelo qual o Helicobacter pylori causa lesão em estômagos humanos é bem conhecido (MARSHAL e WARREN, 1984; BRENNER et al., 2004; ERNST et al., 2006), porém esses estudos são escassos quando se trata de Helicobacter spp em suínos. Uma das características da doença gástrica de humanos causada pela infecção pelo Helicobacter pylori é o seu caráter de cronicidade. Numa escala temporal, talvez os suínos infectados não desenvolveram doenças gástricas devido ao curto tempo de vida. Sabe-se que suínos voltados para a reprodução (matrizes) são mais predispostos a lesões gástricas graves (KOWALCZYK, 1969) e tais lesões podem estar associadas ao Helicobacter spp.

CARVALHO et al. (1999) sugerem que as lesões erosivas e ulcerativas de região glandular devem ter etiologias ou mecanismos de agressão distintos. O Helicobacter spp é uma bactéria que vive em meio ao muco protetor da mucosa gástrica e a região de 
pars esophagea é uma região desprovida de muco protetor. Os fatores de patogenia e os mecanismos de agressão à mucosa gástrica podem agir de forma diferente na pars esophagea e na região glandular de suínos, o que justifica mais investigações sobre a patogenia das lesões gástricas, bem como sobre as espécies de Helicobacter que infectam suínos.

A influência do gênero na freqüência de úlceras gastresofágicas já foi reportada por outros autores (MONTICELLI et al., 1995; CARVALHO et al., 1999). Entretanto, outros estudos não verificaram a relação do gênero e as úlceras gástricas ou qualquer outra doença do estômago dos suínos (GUISE et al., 1997 e PARK et al., 2004). Verificamos que não houve influência do sexo na ocorrência de lesões gástricas, o mesmo relatado por Guise et al. (1997) e Park et al. (2004).

Ao analisarmos o peso médio da carcaça ao abate, dos animais com e sem lesão, observamos que as médias foram semelhantes, não sendo possível relacionar as lesões gástricas com uma diminuição significativa no peso da carcaça. Poucos são os relatos encontrados relacionando lesões gástricas e peso do animal. Kowalczyk (1969) relatou que na forma assintomática da doença gástrica, a taxa de crescimento dos animais é adequada para os padrões da produção industrial. Nesta forma o diagnóstico é feito no abatedouro com a observação de alterações como paraqueratose, erosões ou úlceras. Nossos resultados estão de acordo com o relatado por outros autores e sugerem que mesmo as lesões mais graves (graus 2 e 3) não afetaram significativamente o desenvolvimento dos animais (KOWALCZYK, 1969; FRIENDSHIP, 1999; GUISE et al., 1997).

Desta forma, podemos concluir que a ocorrência de lesões na mucosa gástrica é elevada nos suínos abatidos na região Norte do Estado do Paraná. Apesar da alta ocorrência, não foi possível estabelecer a relação entre a infecção por Helicobacter spp e a presença de tais lesões. Conclui-se também que não houve relação entre a ocorrência de lesões gástricas, o gênero e o peso da carcaça.

\section{Referências}

ARGENZIO, R.A.; EISEMANN, J. Mechanisms of acid injury in porcine gastroesophageal mucosa. Am. J. Vet. Res., v.57, p. 564-573, 1996.

BARBOSA, A.J.A.; SILVA, J.C.P.; NOGUEIRA, M.M.F.; PAULINO Jr., E.; MIRANDA, C.R. Higher incidence of Gastropirillum sp. in swine with gastric ulcer of the pars oesophagea. Vet. Pathol., v.32, p. 134-139, 1995.

BRENNER, H.; ARNDT, V.; STEGMAIER, C.; ZIEGLER, H.; ROTHENBACHER, D. Is Helicobacter pylori infection a necessary condition for noncardia gastric cancer? Am. J. Epidemiol., v. 159. p. 252-258, 2004.

CANTET, F.; MAGRAS, C.; MARAIS, A.; FEDERIGUI, M.; MÉGRAUD, F. Helicobacter species colonizing pig stomach: molecular characterization and determination of prevalence. Enviroment Microbiol., v.65, p. 4672-4676, 1999.

CARVALHO, L.F.O.S.; OLIVEIRA, C.J.B.; MARTINEZ, P.A.O.; MAZZUCATO, B.C.; ALESSI, A.C. Freqüência de lesões gástricas em suínos destinados ao abate na região de Ribeirão Preto, SP. Arq. Bras. Med. Vet. Zootec., v.51, p.223-227, 1999.

CIACCI, J.R.; MORES, N.; SOBESTIANSKY, J. Úlcera gástrica como causa de morte e como achado de necropsia em três rebanhos suínos. Arq. Bras. Med. Vet. Zootec., v.43, p.525-533, 1991 .

DE GROOTE, D.; DUCATELLE, R.; VAN DOORN, L.J; TILMANT, K.; VERSCHUUREN, A.; HAESEBROUCK, F. Detecion of "Candidatus Helicobacter suis" in gastric samples of pig by PCR: comparison with other invasive diagnostic techniques. J. Clin. Microbiol., v. 38, p. 1131$1135,2000$.

EMBAYE, H.; THOMLINSON, J.R.; LAWRENCE, T.L.J. Histopathology of oesophagogastric lesions in pigs. $J$. Comp. Pathol., v.103, p. 253-264, 1990.

ERNST, P. B.; PEURA, D. A.; CROWE, S. E. The translation of Helicobacter pylori basic research to patiet care. Gastroenterol.v. 206, p. 130-188, 2006.

FRIENDSHIP, R.M.; MELNICHOUK, S.; SMART, N.L. Helicobacter infection: what should a swine practitioner know? Swine Health Prod., v.7, p.167-172, 1999.

GRASSO, G.M.; RIPABELLI, G.; SAMMARCO, M.; RUBERTO, A.; IANNETTO, G. Prevalence of Helicobacter-like organisms in porcine gastric mucosa. A study of swine slaughtered in Italy. Comp. Immun. Microbiol. Infect. Dis., v. 19, p. 213-217, 1996. 
GUISE, H.J.; CARLYLE, W.W.H.; PENNY, R.H.C. Gastric ulcers in finishing pigs: their prevalence and failure to influence growth rate. Vet. Rec., v.141, p.563-566, 1997.

KRAKOWKA, S.; RINGS, D. M.; ELLIS, J. A. Experimental induction of bacterial gastritis and gastric ulcer disease in gnotobiotic swine inoculated with porcine Helicobacterlike species. Am. J. Vet. Res., v. 66, p. 945-952, 2005.

KOWALCYZK, T. Etiologic factors of gastric ulcers in swine. Am. J. Vet. Res.,v. 30, n. 3. p. 393-400, 1969.

MALL, A. S.; SULEMAN, N.; TAYLOR, K.; KIDD, M.; TYLER, M.; LOTZ, Z.; ROSEMARY, H.; KAHN, D. The relationship os a Helicobacter heilmannii infection to the mucosal changes in abattoir and laboratory pig stomach. Surg. Today. v. 34, p. 943-949. 2004.

MARSHAL, B. J.; and WARREN, J. R. Unidentified curved bacilli in the stomach of patients with gastritis and peptic ulceration. Lancet, v.1, p. 1311-1314. 1984.

MELNICHOUK, S.I.; FRIENDSHIP, R.M.; DEWEY, C.E.; BILDFELL, R.J.; SMART, N.L. Helicobacter-like organisms in the stomach of pigs with and without gastric ulceration. Swine Health Prod., v.7, p. 201-205, 1999.

MONTICELLI, C.J.; MENTEN, J.F.M.; ZANOTTO, D.L. Efeito da granulometria do milho, da área por animal e do sexo sobre lesões gástricas de suínos. In: Congresso brasileiro de veterinários especialistas em suínos, 7, 1995, Blumenau. Anais..., Blumenau: ABRAVES, 1995, P. 165.

MORÉS, N.; SOBESTIANSKY, J.; LOPES, A. Avaliação Patológica de Suínos no Abate - Manual de Identificação. Embrapa. Brasília, DF. p 22 - 24, 2000.

MUGGENBURG, B.A.; REESE, B.S.; KOWALSKY, M.S.; GRUMMER, R.H.; HOCKSTRA, W.G. Survey of the prevalence of gastric ulcers in swine. Am. J. Vet. Res., v.25, p.1673-1678, 1964.
O'BRIEN, J.J. Gastric ulcers. In: LEMAN, A.D.; STRAW, B.E.; MENGELING, W.L. et al. Diseases of Swine. 7 ed. Ames, Iowa State University Press, 1993. p.680-691.

PARK, J. -H.; SEOK, S.-H.; CHO, S. -A.; BAEK, M.-W.; LEE, H. -Y.; KIM, D. -J.; PARK, J.-H. The hight prevalence of Helicobacter sp. in porcine pyloric mucosa and its histopathological and molecular characteristics. Vet. Microbiol. v.104, p. 219-225. 2004.

QUEIROZ, D.M.M.; ROCHA, G.F.; MENDES, E.N.; LAGE, A.P.; CARVALHO, C.T.; BARBOSA, A.J.A. A spiral microorganism in the stomach of pigs. Vet. Microbiol., v.24,p. 199-204, 1990.

QUEIROZ, D.M.M.; ROCHA, G.F.; MENDES, E.N.; MOURA, S.B.; OLIVEIRA, A.M.R.; MIRANDA. D. Association between Helicobacter and gastric ulcer disease of the pars esophagea in swine. Gastroenterol., v.27, p.111-119, 1996.

ROPPA, L.; SARTOR, A.B.; OTONELLI, J. Ocorrência de úlcera gastroesofágica em suínos ao abate no Brasil. In: Congresso Brasileiro de Veterinários Especialistas em Suínos, 7, 1995, Blumenau. Anais...Blumenau: ABRAVES, 1995. p.108.

SIMPSON, K.W.; MC DONOUGH, P.L.; STRAUSSAYALI, D.; CHANG, Y.F.; HARPENDING, P.; VALENTINE, B.A. Helicobacter felis infection in dogs: effect on gastric structure and function. Vet. Pathol., v.36, p. 237-248, 1999.

SZEREDI, L.; PALKOVICS, G.; SOLYMOSI, N.; TEKES, L.; MEHESFALVI, J. Study on the role of gastric Helicobacter infection in gross pathological and histological lesions of the stomach in finishing pigs. Acta Vet Hung., v.53, p. 371-83, 2005.

YOUNG, Y. K.; HAN, J. H.; JOO, H.S. Identification of novel Helicobacter species in pig stomachs by PCR and partial sequencing. J. Clin. Microbiol., Vol. 39, p. 3311-3315, 2001. 